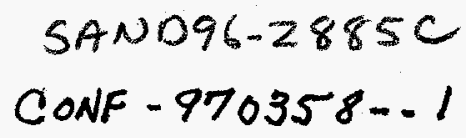

A Complete Monolithically-Integrated Circuit for All-Optical Generation of Millimeter-Wave Frequencies

\author{
G. Allen Vawter, Alan Mar, Vince Hietala, John Zolper \\ Sandia National Laboratories, Albuquerque, NM 87185-0603, USA \\ (505) 844-9004, (505) 844-8985 fax \\ RECEIVED \\ JAN $O 61997$ \\ Q.S.TI
}

A optoelectronic integrated circuit for generation of mm-wave frequencies is demonstrated and design issues detailed. A monolithically integrated ring laser, optical amplifier and photodiode generate electrical signals up to $85.2 \mathrm{GHz}$.

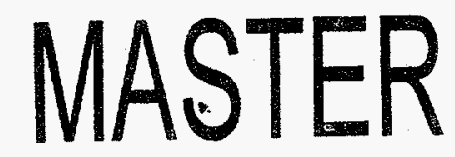

NISTPIBUTON OF THS DCOUMENT IS UNLMITED

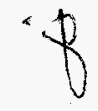




\section{DISCLAIMER}

This report was prepared as an account of work sponsored by an agency of the United States Government. Neither the United States Government nor any agency thereof, nor any of their employees, make any warranty, express or implied, or assumes any legal liability or responsibility for the accuracy, completeness, or usefulness of any information, apparatus, product, or process disclosed, or represents that its use would not infringe privately owned rights. Reference herein to any specific commercial product, process, or service by trade name, trademark, manufacturer, or otherwise does not necessarily constitute or imply its endorsement, recommendation, or favoring by the United States Government or any agency thereof. The views and opinions of authors expressed herein do not necessarily state or reflect those of the United States Government or any agency thereof. 
DISCLAMMER

Portions of this document may be illegible in electronic image products. Images are produced from the best available original document. 


\title{
A Complete Monolithically-Integrated Circuit for All-Optical Generation of Millimeter-Wave Frequencies
}

\author{
G. Allen Vawter, Alan Mar, Vince Hietala, John Zolper \\ Sandia National Laboratories, Albuquerque, NM 87185-0603, USA \\ (505) 844-9004, fax:(505)844-8985
}

All optical generation of mm-wave signals has the potential for dramatic improvements in efficiency compared to current solid-state electronic sources, such as negative-differentialresistance diodes, at frequencies well above $60 \mathrm{GHz}$. The high quantum efficiency of passive mode-locked diode lasers and rib waveguide optical amplifiers coupled with the power-handling capability and efficiency of traveling-wave photodiodes ${ }^{1-3}$ (TWPD) suggests that mm-wave source with 30 to $50 \%$ efficiency and greater than $10 \mathrm{dBm}$ output at frequencies up to $200 \mathrm{GHz}$ is a possibility.

We demonstrate the first such compact optoelectronic integrated circuit (OEIC) for generation of $\mathrm{mm}$-wave frequencies. This new OEIC integrates a passively mode-locked semiconductor ring laser ${ }^{4}$, optical amplifier and high-speed photodiode for generation, amplification and detection of an optical pulse train with 30 to $90 \mathrm{GHz}$ pulse-repetition frequency. Output of the OEIC is an electrical signal, generated by the photodiode, whose fundamental frequency is the pulse repetition rate of the mode-locked laser. Such lasers have been demonstrated up to $172 \mathrm{GHz}$ pulse repetition frequency. The circuit uses a novel waveguide photodiode (WGPD) integrated with a mm-wave transmission line specifically designed for high-speed operation and signal extraction on a heavilydoped GaAs substrate. Issues influencing the design of the WGPD and transmission line will be presented.

The mm-wave generation OEIC (Fig. 1) uses (Al,Ga)As double-heterostructure rib waveguides with a single-quantum-well active region. Multi-lateral-mode ring waveguides with Y-junction output couplers are etched to form passively mode-locked lasers monolithically integrated with an optical amplification section and WGPD at the laser output. Pulse repetition frequency is fixed by the ring diameter and saturable absorber configuration; we have demonstrated 30,60 and $90 \mathrm{GHz}$ circuits. The WGPD is formed using a trench etch around the rib waveguide and is integrated with an electrical transmission line for efficient removal of the output signal. The WGPD was chosen instead of an electrically distributed TWPD so that the photodiode would use the same epitaxial material as the laser and amplifier. Figure 2 shows cross sections of all parts of the circuit including the $50 \mathrm{Ohm}$ transmission line used for signal extraction from the WGPD.

The RF output spectrum of each OEIC is plotted in Fig. 3. Fundamental pulse repetition frequency of the 860,430 and $290 \mu \mathrm{m}$ diameter of rings were $29.1,57.5$ and $85.2 \mathrm{GHz}$ respectively. Frequency generation close to the desired value was achieved for all three laser diameters. The observed linewidth is dominated by the approximate $900-p s e c$ rms pulse-to-pulse timing jitter. Such values are not unusual for passively mode-locked semiconductor lasers. Peak $\mathrm{mm}$-wave power levels are $-12,-23$ and $-27 \mathrm{dBm}$ at $29.1,57.5$ and $85.2 \mathrm{GHz}$ respectively.

This circuit demonstrates the feasibility of mm-wave signal generation using a mode-locked ring laser OEIC. Output power of these circuits is influenced by a number of factors including the internal circulating power of the ring, the amount of power coupled out of the ring, the gain of the amplifier, and the efficiency of the photodiode. Efficiency of the photodiode is limited to $10 \%$ at the highest frequencies due to the short length required for low-capacitance and high-speed operation. A TWPD would improve the output power tenfold although epitaxial regrowth of the TWPD may be required to achieve the correct $p n$-junction depletion width for velocity-matched operation. Optimizing the output coupler for power extraction from the ring and using a flared 
amplifier with one or more photodiodes operating in parallel at the wide amplifier output end may result in further power enhancements by as much as a factor of 100 . Some possible configurations of an improved OEIC for higher-power operation will be discussed.

In summary, we have demonstrated a new type of OEIC for direct generation of mm-wave frequencies. This OEIC integrates a passively mode-locked semiconductor ring laser with an optical amplifier and high-speed waveguide photodiode. OEICs using this concept could be used in a wide variety of applications where a very compact, lightweight mm-wave source is required. This work was supported by United States Department of Energy under Contract DE-AC0494AL85000. Sandia is a multiprogram laboratory operated by Sandia Corporation, a LockheedMartin Company, for the United States Department of Energy.

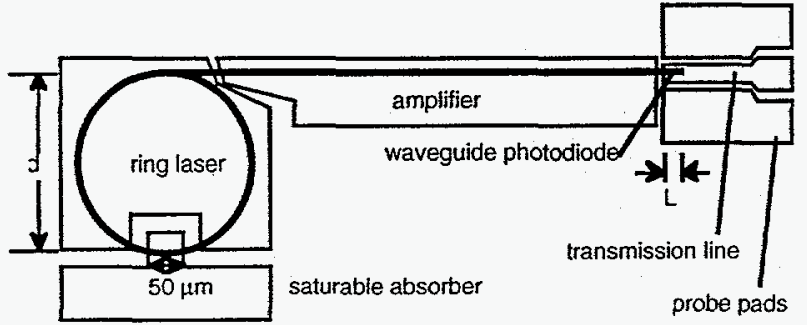

Figure 1: Schematic view of millimeter-wave generation OEIC. L is WGPD length and $d$ the ring laser diameter.

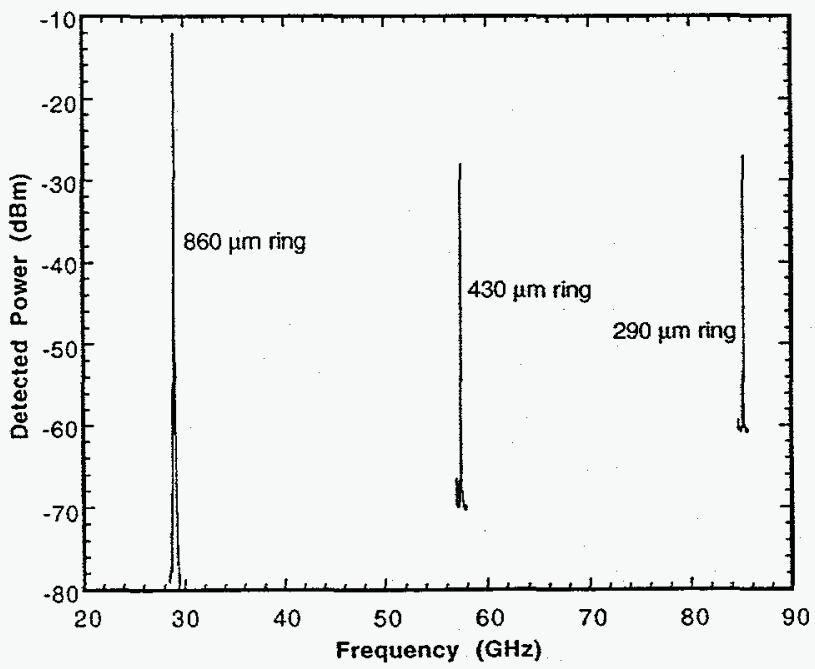

Figure 3: Measured electrical output spectrum of three different millimeter-wave generation OEICs. Ring laser diameter determines the output frequency of circuit.
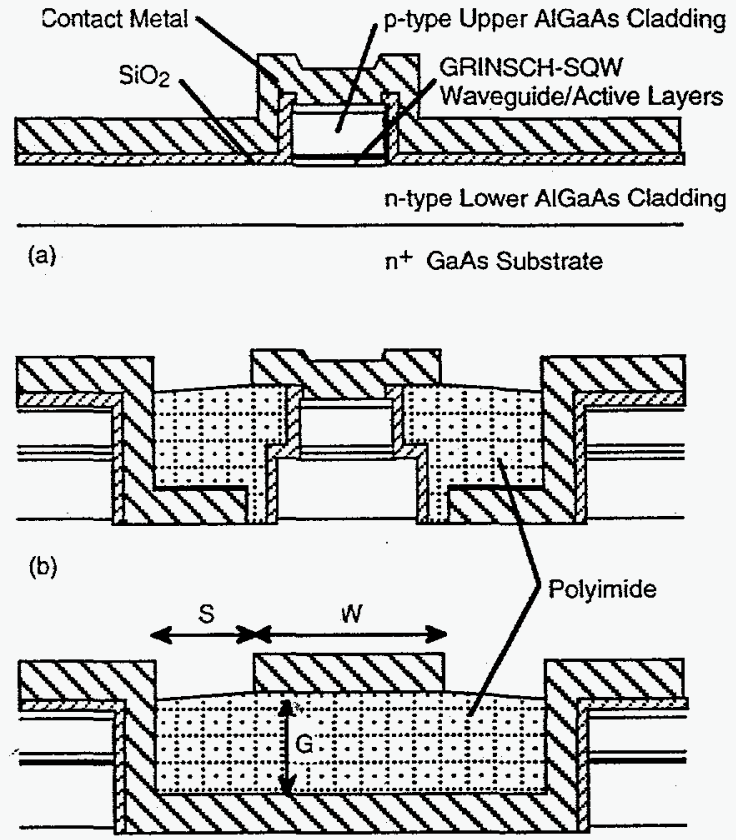

(c)

Figure 2: Cross section diagram of laser and amplifier, (a), WGPD, (b), and transmission line, (c).

References

1) V. M. Hietala, G. A. Vawter, T. M. Brennan and B. E. Hammons, IEEE Trans. on Microwave Th. and Tech. 43, 2291-2297 (1995).

2) K. S. Giboney, R. L. Nagarajan, T. E. Reynolds, S. T. Allen, R. P. Mirin, M. J. Rodwell and J. E. Bowers, IEEE Phot. Technol. Lett. 7, 412-414 (1995).

3) L. Y. Lin, M. C. Wu, T. Itoh, T. A. Vang, R. E. Muller, D. L. Sivco and A. Y. Cho, IEEE Phot. Technol. Lett. 8, 1376-1378 (1996).

4) J. P. Hohimer and G. A. Vawter, Appl. Phys. Lett. 63, 1598-1600 (1993). 